Check for updates

Cite this: RSC Adv., 2017, 7, 27377

Received 27th March 2017 Accepted 18th May 2017

DOI: 10.1039/c7ra03534a

rsc.li/rsc-advances

\section{A binary polymer composite of graphitic carbon nitride and poly(diphenylbutadiyne) with enhanced visible light photocatalytic activity}

\author{
Juying Lei, (D) ${ }^{a}$ Fenghui Liu, ${ }^{\mathrm{b}}$ Lingzhi Wang, (D) ${ }^{\mathrm{b}}$ Yongdi Liu*a and Jinlong Zhang (D) *bc \\ New polymer composites consisting of poly(diphenylbutadiyne) (PDPB) and $g-\mathrm{C}_{3} \mathrm{~N}_{4}$ have been successfully \\ prepared. UV-vis diffuse reflectance spectra show that the existence of PDPB in composites can clearly \\ increase the visible light absorption of the catalysts. Photoluminescence spectroscopy and \\ photoelectrochemical measurements reveal that PDPB can effectively facilitate the charge carrier \\ separation in the composites. Compared with pure $\mathrm{g}-\mathrm{C}_{3} \mathrm{~N}_{4}$ or pure PDPB, the composite catalysts \\ exhibit observably enhanced visible-light photocatalytic activity for degradation of RhB and phenol. A \\ possible mechanism for the charge separation and transfer in the composite catalysts is proposed. In \\ addition, the composite catalysts show stable catalytic performance after five successive runs, displaying \\ potential for applications in various fields of photocatalysis.
}

\section{Introduction}

Using semiconductor photocatalysts to degrade organic pollutants has attracted much attention due to the global energy crisis and environment pollution. ${ }^{1-3}$ To date, a variety of environmentally responsible photocatalysts have been developed, including $\mathrm{TiO}_{2},{ }^{4-7} \mathrm{ZnO}^{8,9} \mathrm{CdS}^{10,11}$ and so on. In particular, graphitic carbon nitride $\left(\mathrm{g}-\mathrm{C}_{3} \mathrm{~N}_{4}\right)$, a novel metal-free material with a special layered structure, has unique properties, such that it is considered to be an ideal material for photocatalysis. $^{12,13}$ In 2009, Wang et al. first reported that $\mathrm{g}-\mathrm{C}_{3} \mathrm{~N}_{4}$ has excellent photocatalytic ability. ${ }^{\mathbf{1 4}}$ Since then, the catalytic performance of $\mathrm{g}-\mathrm{C}_{3} \mathrm{~N}_{4}$ for the photocatalytic degradation of organic pollutants in water has been extensively studied.

However, the $\mathrm{g}-\mathrm{C}_{3} \mathrm{~N}_{4}$ has many weak points such as the small surface area, high recombination rate of photogenerated electron-hole pairs and low visible light utilization efficiency. ${ }^{15}$ Hence, various methods have been used to solve these problems, for example, synthesizing different structures, ${ }^{\mathbf{1 6 , 1 7}}$ doping with metal or nonmetal elements, ${ }^{18-21}$ coupling with other semiconductors, ${ }^{22-26}$ and modifying by conjugated polymers. ${ }^{27,28}$ Among these methods, the conjugated polymer modification has attracted many attentions because the conjugated polymer

\footnotetext{
${ }^{a}$ State Environmental Protection Key Laboratory of Environmental Risk Assessment and Control on Chemical Process, School of Resources and Environmental Engineering, East China University of Science and Technology, 130 Meilong Road, Shanghai 200237, P. R. China. E-mail: ydliu@ecust.edu.cn

${ }^{b}$ Key Lab for Advanced Materials, Institute of Fine Chemicals, School of Chemistry and Chemical Engineering, East China University of Science and Technology, 130 Meilong Road, Shanghai 200237, P. R. China.E-mail: jlzhang@ecust.edu.cn

${ }^{c}$ Suzhou Jukang New Materials Co. Ltd, 558 Fenhu Road, Suzhou, Jiangsu Province 201211, P. R. China
}

not only can enhance the absorption of the visible light but also can act as a semiconductor. Yan et al. synthesized carbon nitride-poly(3-hexylthiophene) $\left(\mathrm{g}-\mathrm{C}_{3} \mathrm{~N}_{4}-\mathrm{P}_{3} \mathrm{HT}\right)$ composite photocatalyst. ${ }^{24}$ They found that the novel photocatalyst exhibited significantly enhanced photocatalytic activity. Thakare et al. reported on the synthesis of a ternary polymer composite of graphene, carbon nitride, and poly(3-hexylthiophene) (G-g$\mathrm{C}_{3} \mathrm{~N}_{4}-\mathrm{P}_{3} \mathrm{HT}$ ) which had enhanced photocatalytic activity. ${ }^{29} \mathrm{Ge}$ et al. prepared a novel polyaniline-graphitic carbon nitride (PANI/g- $-\mathrm{C}_{3} \mathrm{~N}_{4}$ ) composite photocatalyst which had intensive visible light photocatalytic activity. ${ }^{30}$ Wang et al. prepared an efficient visible-light photocatalyst using g- $\mathrm{C}_{3} \mathrm{~N}_{4}$ and ordinary polyvinyl chloride (PVC) as main precursors. ${ }^{28}$ However, to the best of our knowledge, the report about using polymer modified $\mathrm{g}-\mathrm{C}_{3} \mathrm{~N}_{4}$ is still scarce.

Poly(diphenylbutadiyne) (PDPB) is a newly developed polymer semiconductor which was reported by Hynd Remita in $2015 .^{31}$ The PDPB obtained by $\pi$-stacking of oligomers presents a high photocatalytic activity and long-term stability. Recent research has also shown that the composite of PDPB and semiconductor $\mathrm{ZnO}$ exhibited high visible light photocatalytic activity, ${ }^{32}$ due to the visible light harvesting of PDPB. Inspired by this, we speculate that if we combine PDPB with $\mathrm{g}-\mathrm{C}_{3} \mathrm{~N}_{4}$, based on the good visible light absorption of $\mathrm{g}-\mathrm{C}_{3} \mathrm{~N}_{4}$ itself, the combination of $\mathrm{g}-\mathrm{C}_{3} \mathrm{~N}_{4}$ and PDPB will bring a better absorption of visible light, leading to a better visible light activity.

Herein, we prepare a polymer composite photocatalyst consisting of $\mathrm{g}-\mathrm{C}_{3} \mathrm{~N}_{4}$ and PDPB (CN-PDPB). The photocatalytic activity is investigated by evaluating the photocatalytic degradation of Rhodamine B (RhB) and phenol. The results exhibit that the CN-PDPB has higher photocatalytic activity than pure $\mathrm{g}-\mathrm{C}_{3} \mathrm{~N}_{4}$ and PDPB. It is maybe because the existence of PDPB can 
obviously improve the absorption of $\mathrm{g}-\mathrm{C}_{3} \mathrm{~N}_{4}$ in the visible light range. What's more, the interaction between $g-\mathrm{C}_{3} \mathrm{~N}_{4}$ and PDPB improves the separation efficiency of the photo-generated charge carriers. In addition, the composites catalysts show stable catalytic performance after five successive runs.

\section{Experimental}

The preparation of photocatalysts

$\mathrm{g}^{-} \mathrm{C}_{3} \mathrm{~N}_{4}$ was synthesized by directly heating melamine powder. Melamine powder was put into a covered alumina crucible and heated in a muffle furnace. Firstly, the powder was heated to $500{ }^{\circ} \mathrm{C}$ with a heating temperature rate of $2{ }^{\circ} \mathrm{C} \mathrm{min}^{-1}$ and kept at this temperature for $2 \mathrm{~h}$, then heated to $520^{\circ} \mathrm{C}$ within $10 \mathrm{~min}$ and kept at this temperature for $2 \mathrm{~h}$. Finally, we obtained a light yellow $\mathrm{g}-\mathrm{C}_{3} \mathrm{~N}_{4}$. The product was ground to powder for further usage.

PDPB was synthesized following the previously method published by Hynd Remita. ${ }^{31}$

The composite catalysts of $\mathrm{g}-\mathrm{C}_{3} \mathrm{~N}_{4}$ and PDPB were prepared by impregnating g- $\mathrm{C}_{3} \mathrm{~N}_{4}(0.5 \mathrm{~g})$ with an ethanol solution of PDPB for a night, and then the solvent was vapored in oil bath at 363 $\mathrm{K}$. The resultant samples were labeled as $50: x \mathrm{CN}-\mathrm{PDPB}$, where $50: x$ was the mass ratio of $g-\mathrm{C}_{3} \mathrm{~N}_{4}$ and PDPB in the abovementioned process for preparation of $\mathrm{CN}-\mathrm{PDPB}$ photocatalysts.

\section{Photocatalytic activity test}

The photocatalytic activity of the samples was tested by degradation of RhB dyes and phenol at room temperature using a $300 \mathrm{~W}$ xenon lamp with AM 1.5 or $420 \mathrm{~nm}$ filter as light source. $10 \mathrm{mg}$ of catalyst powder was added to the $50 \mathrm{~mL}$ of $10 \mathrm{mg} \mathrm{L}^{-1}$ $\mathrm{RhB}$ (or phenol) aqueous solution. Before irradiation, the suspensions were continuously stirred for $30 \mathrm{~min}$ in the dark in order to reach an adsorption-desorption equilibrium. At given time intervals, aliquots of the irradiated suspension were collected and centrifuged. The RhB was analyzed by the UV-vis spectra at $553 \mathrm{~nm}$ and the phenol was analyzed by a HPLC system.

\section{Results and discussion}

\section{Morphology and structural properties}

To confirm the structure and morphology of the polymer composites, the g- $\mathrm{C}_{3} \mathrm{~N}_{4}$ and the polymer composite $50: 2 \mathrm{CN}-$ PDPB were observed by TEM. As shown in Fig. 1, both pure g$\mathrm{C}_{3} \mathrm{~N}_{4}$ and $50: 2 \mathrm{CN}-\mathrm{PDPB}$ display layered structure. Pure g- $\mathrm{C}_{3} \mathrm{~N}_{4}$ (Fig. 1a) exhibits a flat and smooth surface and it became rough after the modification of PDPB (Fig. 1b). It can be seen clearly that the PDPB distributes on the surface of $\mathrm{g}^{-} \mathrm{C}_{3} \mathrm{~N}_{4}$. In addition to TEM, other characterizations were also carried out to prove the existence of PDPB in the composite CN-PPDB.

Fig. 2 shows the wide-angle XRD patterns of pure PDPB, pure $\mathrm{g}^{-} \mathrm{C}_{3} \mathrm{~N}_{4}$ and $\mathrm{CN}-\mathrm{PDPB}$ photocatalysts. The peak at $27.7^{\circ}$ in the XRD pattern of $g-\mathrm{C}_{3} \mathrm{~N}_{4}$ coming from the interlayer stacking of aromatic segments can be indexed as the (002) planes. Another pattern at $13.1^{\circ}$ indexed as (100) planes is due to the in-plane structural packing motif. ${ }^{5,33,34}$ From the XRD patterns of CNPDPB photocatalysts, we can see that the two characteristic

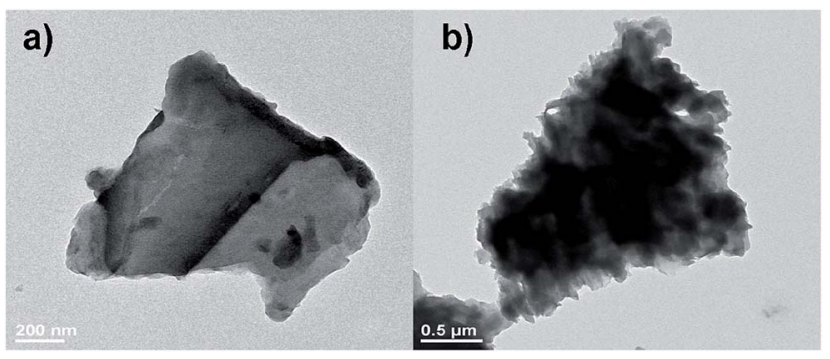

Fig. 1 TEM images of (a) $\mathrm{g}-\mathrm{C}_{3} \mathrm{~N}_{4}$ and (b) $50: 2 \mathrm{CN}-\mathrm{PDPB}$
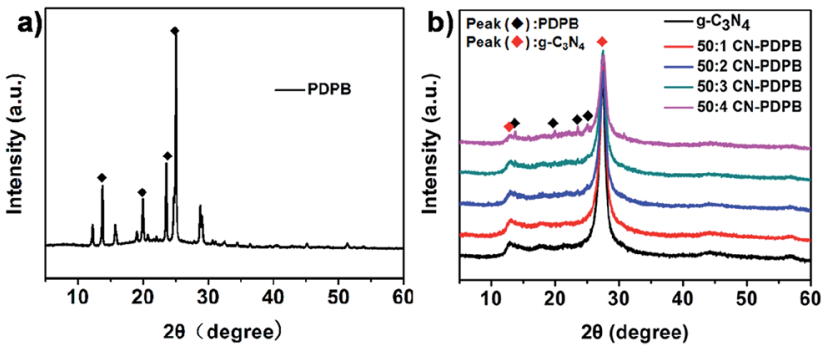

Fig. 2 Wide-angle XRD patterns of (a) PDPB, (b) $g-\mathrm{C}_{3} \mathrm{~N}_{4}$ and $\mathrm{CN}-$ PDPB.

peaks of $\mathrm{g}-\mathrm{C}_{3} \mathrm{~N}_{4}$ are clearly observed, indicating that PDPB does not change the crystalline structure of $\mathrm{g}-\mathrm{C}_{3} \mathrm{~N}_{4}$. However, the characteristic patterns of PDPB are not observed at first because of its low content in the composites but with the increase of content of PDPB, the XRD of $50: 4$ CN-PDPB displays patterns at $14^{\circ}, 20.4^{\circ}, 23.6^{\circ}, 24.7^{\circ}$, which are ascribed to the characteristic patterns of PDPB. ${ }^{31}$ This results further confirm the existence of PDPB in the CN-PDPB composites.

The surface chemical environment of the catalysts is analyzed by XPS. Fig. 3a and b show the C 1s XPS spectra of $\mathrm{g}$ $\mathrm{C}_{3} \mathrm{~N}_{4}$ and $50: 2 \mathrm{CN}-\mathrm{PDPB}$, respectively. In Fig. $3 \mathrm{~b}$, the $\mathrm{C} 1 \mathrm{~s}$ has two peaks at 284.8 and $288.1 \mathrm{eV}$. The C peak at $284.8 \mathrm{eV}$ corresponds to graphitic carbon, which is usually observed in the XPS spectrum of carbon nitrides. ${ }^{35}$ The peak at $288.1 \mathrm{eV}$ is ascribed to the $\mathrm{sp}^{2}$-bonded carbon $(\mathrm{N}-\mathrm{C}=\mathrm{N})$ from carbon nitride and carbon atoms in conjugated structure $(-\mathrm{C}=\mathrm{C}-)$ from PDPB. ${ }^{28,36-39}$ Compared with Fig. 3a, the intensity ratio of the peaks at $284.8 \mathrm{eV}$ and $288.1 \mathrm{eV}$ in Fig. $3 \mathrm{~b}$ reduces, indicating the existence of $-\mathrm{C}=\mathrm{C}-$ on the surface of $50: 2 \mathrm{CN}-\mathrm{PDPB}$. This
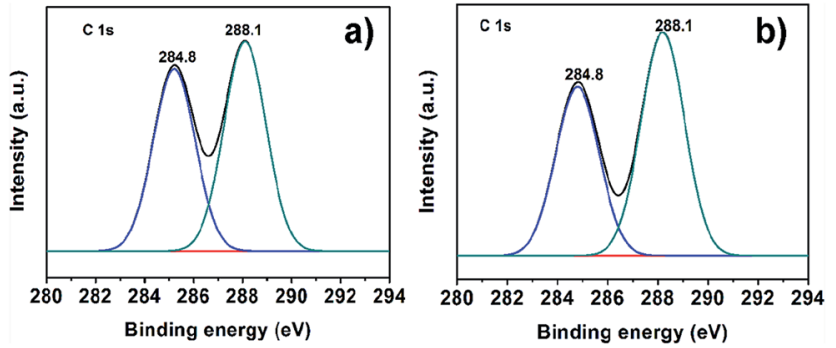

Fig. 3 The XPS spectra of (a) $\mathrm{C} 1 \mathrm{~s}$ of $\mathrm{g}-\mathrm{C}_{3} \mathrm{~N}_{4}$ and (b) $\mathrm{C}$ 1s of $50: 2 \mathrm{CN}-$ PDPB. 


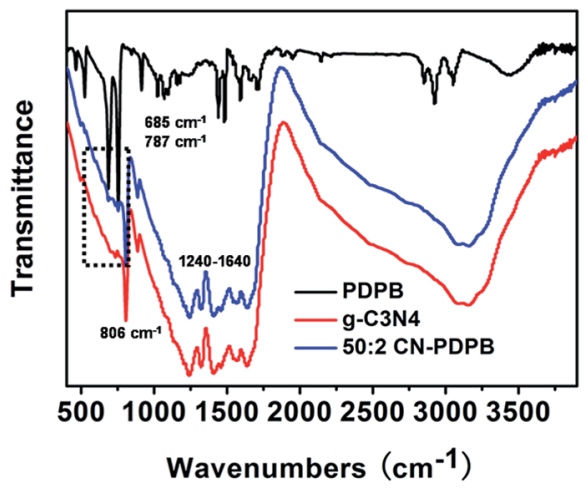

Fig. 4 FTIR spectra of PDPB, $g-\mathrm{C}_{3} \mathrm{~N}_{4}$ and $50: 2 \mathrm{CN}-\mathrm{PDPB}$

further confirms the existence of PDPB in the composite CNPDPB.

Fig. 4 shows the FTIR spectra of PDPB, g- $\mathrm{C}_{3} \mathrm{~N}_{4}$ and $50: 2 \mathrm{CN}-$ PDPB. For $\mathrm{g}^{-} \mathrm{C}_{3} \mathrm{~N}_{4}$, the strong bands at 1241, 1322, 1406, 1571, and $1631 \mathrm{~cm}^{-1}$ are corresponding to the typical stretching modes of $\mathrm{CN}$ heterocycles and the band at $806 \mathrm{~cm}^{-1}$ is attributed to the characteristic breathing mode of triazine units. Compared with the FTIR of PDPB and g- $\mathrm{C}_{3} \mathrm{~N}_{4}$, the FTIR band at $685 \mathrm{~cm}^{-1}$ and $787 \mathrm{~cm}^{-1}$ can be found in $50: 2 \mathrm{CN}-\mathrm{PDPB}$ which is consistence with the previous report ${ }^{31}$ but the intensities of the peaks are weak. That is because the low content of PDPB in $50: 2 \mathrm{CN}-\mathrm{PDPB}$. All of these prove the existence of PDPB in $50: 2$ CN-PDPB.

The UV-vis diffuse reflectance spectrum for the catalysts in Fig. 5 shows that the absorption of the CN-PDPB composites is higher than that of pure $\mathrm{g}-\mathrm{C}_{3} \mathrm{~N}_{4}$ in the range of $360-800 \mathrm{~nm}$ due to the existence of PDPB. Furthermore, the absorption intensity of the CN-PDPB increases with the increase of PDPB content. This improved absorption is helpful to the improvement of the photocatalytic activity of g- $\mathrm{C}_{3} \mathrm{~N}_{4}$.

\section{Photocatalytic performances}

In order to evaluate the photocatalytic activity of the assynthesized samples, a test reaction is carried out for the degradation of $10 \mathrm{mg} \mathrm{L}^{-1}$ of $\mathrm{RhB}$ with $10 \mathrm{mg}$ of the catalyst

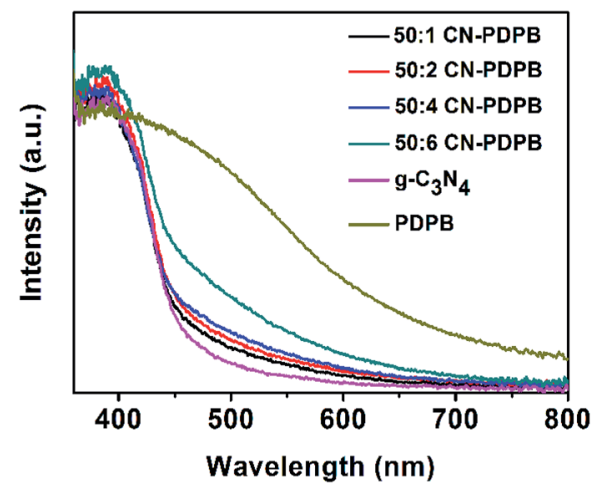

Fig. 5 UV-vis diffuse reflectance spectra of pure $\mathrm{g}-\mathrm{C}_{3} \mathrm{~N}_{4}$ and $\mathrm{CN}-$ PDPB composites.
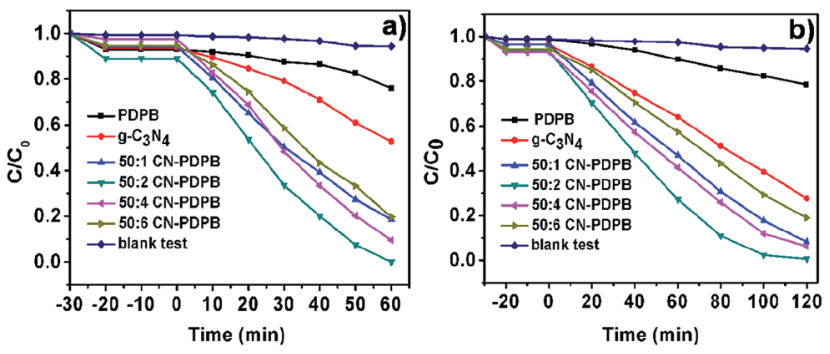

Fig. 6 Photocatalytic degradation of RhB over different catalysts (a) under simulated sunlight (with AM 1.5), (b) under visible light irradiation $(\lambda>420 \mathrm{~nm})$.

under simulated sunlight or visible light and the results are shown in Fig. 6. In addition, Fig. 7 is the UV-vis spectra of the degraded RhB using the $50: 2$ CN-PDPB under simulated sunlight (with AM 1.5). As can be seen from Fig. 6, no matter under irradiation of simulated sunlight or visible light, the photocatalytic degradation of RhB with the CN-PDPB composites is clearly higher than that of the pure g- $\mathrm{C}_{3} \mathrm{~N}_{4}$ and the pure PDPB. The reason may be ascribed to that the combination of $\mathrm{g}-$ $\mathrm{C}_{3} \mathrm{~N}_{4}$ and PDPB can improve the separation efficiency of the photo-generated electrons and holes, meaning the recombination of electrons and holes is inhibited. However, from Fig. 6 we can also find that with the content of PDPB increased, the photocatalytic activity of CN-PDPB composites increases at first and then decreases, and the $50: 2 \mathrm{CN}-\mathrm{PDPB}$ shows the highest photocatalytic activity. This is because with the contents of PDPB increase, extra PDPB will hinder the light exposed to $g$ $\mathrm{C}_{3} \mathrm{~N}_{4}$ and less g- $\mathrm{C}_{3} \mathrm{~N}_{4}$ can be excited to generate electron-hole pairs. As a result, the catalytic activity is reduced. Therefore, there is an optimal ratio to achieve the best photocatalytic activity.

In addition, we use TOC measurement to further confirm the degree of mineralization of RhB solution. The RhB solution is almost decolorized after $60 \mathrm{~min}$ irradiation (in Fig. 6a) and about 30\% removal of TOC has been seen in Fig. 8, manifesting that $\mathrm{RhB}$ has been not only decolorized but also mineralized partly.

Phenol was chosen as another model pollutant to eliminate the sensitization effect of RhB. ${ }^{5}$ Fig. 9 presents the results of

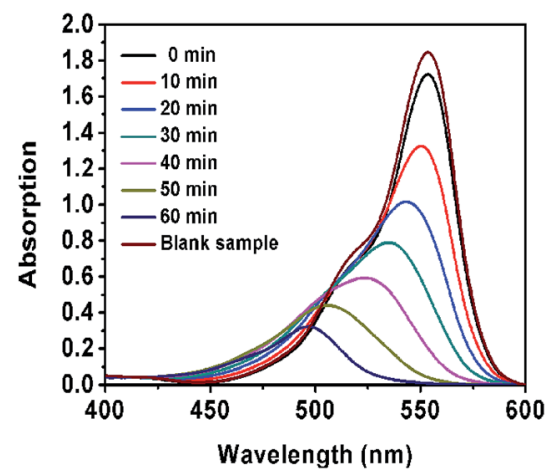

Fig. 7 The UV-vis spectra of the degraded RhB using the $50: 2 \mathrm{CN}-$ PDPB under simulated sunlight (with AM 1.5). 


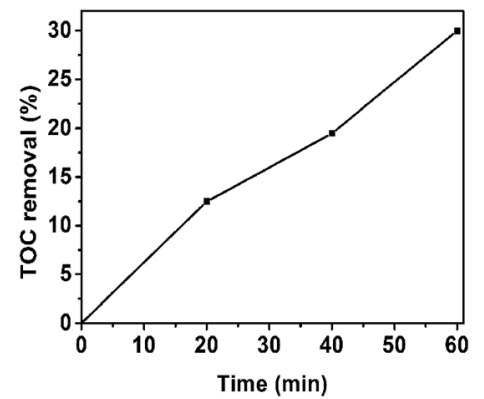

Fig. 8 TOC removal of RhB solution in the presence of $50: 2 \mathrm{CN}-$ PDPB.

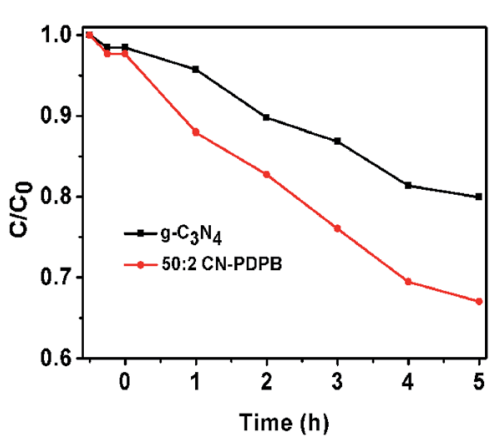

Fig. 9 Photocatalytic degradation of phenol over different catalysts under visible light irradiation.

photocatalytic degradation of phenol catalyzed by pure $\mathrm{g}-\mathrm{C}_{3} \mathrm{~N}_{4}$ and $50: 2 \mathrm{CN}-\mathrm{PDPB}$ under visible light irradiation. We can see that the photocatalytic degradation efficiency of phenol with $50: 2 \mathrm{CN}-\mathrm{PDPB}$ is obviously higher than that of pure $\mathrm{g}-\mathrm{C}_{3} \mathrm{~N}_{4}$, further illustrating that the composite has increscent photocatalytic activity. In addition, we use TOC measurement to further confirm the degree of mineralization of phenol solution. From Fig. 10, it can be seen that the TOC removal values are increased. The degradation of phenol takes time until being finally mineralized.

\section{Mechanism for the enhanced photocatalytic activity}

To investigate the mechanism for the enhancement of the photocatalytic activity by the modification of $g-\mathrm{C}_{3} \mathrm{~N}_{4}$ with PDPB,

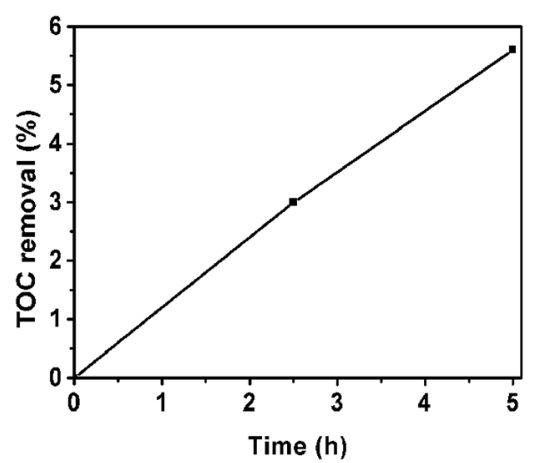

Fig. 10 TOC removal of phenol solution in the presence of $50: 2 \mathrm{CN}-$ PDPB.

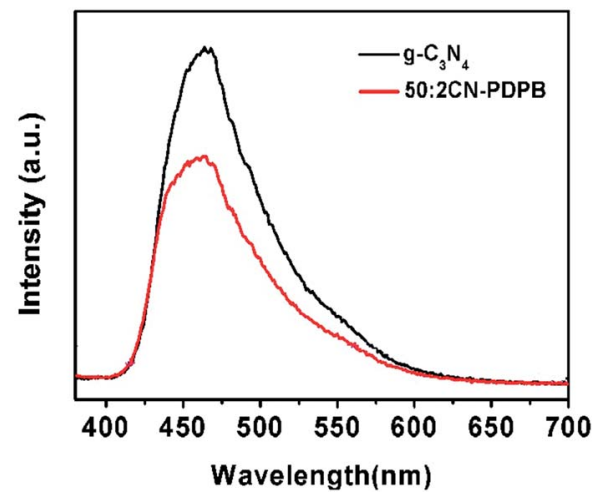

Fig. 11 Photoluminescence spectra of $\mathrm{g}-\mathrm{C}_{3} \mathrm{~N}_{4}$ and $50: 2 \mathrm{CN}-\mathrm{PDPB}$.

photoluminescence (PL) spectra were measured. Fig. 11 shows the results of PL spectra of pure $\mathrm{g}-\mathrm{C}_{3} \mathrm{~N}_{4}$ and $50: 2 \mathrm{CN}-\mathrm{PDPB}$ excited at $360 \mathrm{~nm}$. As can be seen from the figure, the pure $\mathrm{g}$ $\mathrm{C}_{3} \mathrm{~N}_{4}$ exhibits a PL emission band at $460 \mathrm{~nm}$. In comparison, the PL intensity of $50: 2 \mathrm{CN}-\mathrm{PDPB}$ composites is lower than that of g- $\mathrm{C}_{3} \mathrm{~N}_{4}$ due to the easy transfer of carriers between $\mathrm{g}-\mathrm{C}_{3} \mathrm{~N}_{4}$ and PDPB, indicating the increase in the separation efficiency of photo-generated electron-hole pairs. ${ }^{\mathbf{4 0 - 4 2}}$

Besides the photoluminescence measurement, electrochemical impedance spectroscopy (EIS) is also applied to investigate the charge transfer resistance of the catalysts. ${ }^{\mathbf{4 3 - 4 5}}$ The EIS results of prepared samples are presented in Fig. 12 in the form of Nyquist plots. It can be clearly found that the $\mathrm{g}-\mathrm{C}_{3} \mathrm{~N}_{4}$ has the highest charge transport resistance for its biggest arc radius and the arc radius of $\mathrm{CN}-\mathrm{PDPB}$ is significantly smaller than that of the pure $\mathrm{g}-\mathrm{C}_{3} \mathrm{~N}_{4}$. In addition, the $50: 2 \mathrm{CN}-\mathrm{PDPB}$ has the smallest arc radius among the prepared materials, revealing an effective separation of photogenerated electronhole pairs and faster charge transfer occurred on $50: 2 \mathrm{CN}-$ PDPB.

To further investigate the photocatalytic mechanism of the $\mathrm{CN}-\mathrm{PDPB}$, the transient photocurrent responses of pure $\mathrm{g}-\mathrm{C}_{3} \mathrm{~N}_{4}$ and $50: 2 \mathrm{CN}-\mathrm{PDPB}$ were tested by on-off cycles of irradiation.

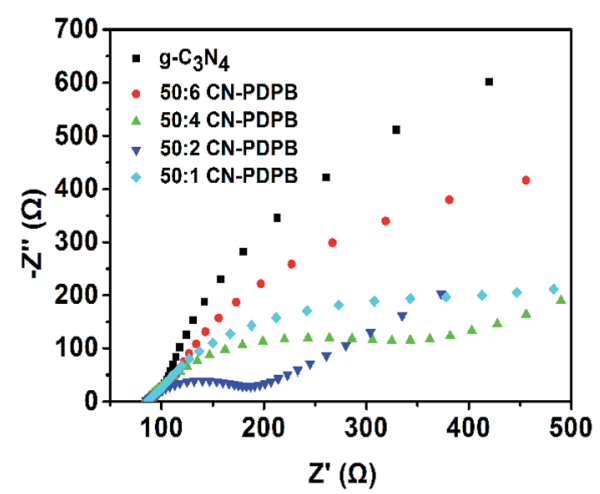

Fig. 12 Electrochemical impedance spectroscopy of $\mathrm{g}-\mathrm{C}_{3} \mathrm{~N}_{4}$ and $\mathrm{CN}-\mathrm{PDPB}$ photocatalysts. 


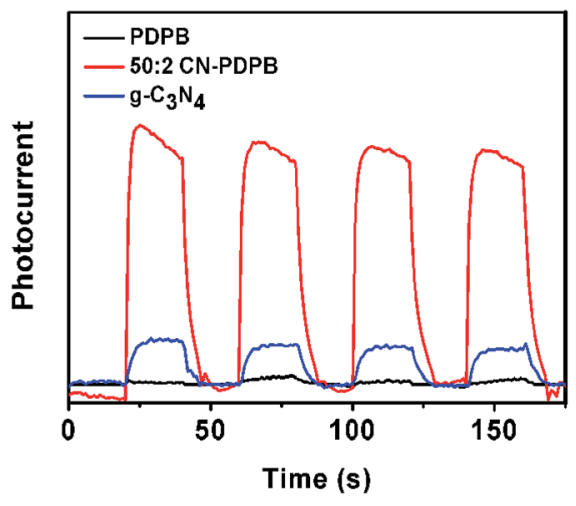

Fig. 13 Transient photocurrent response for PDPB, $g-\mathrm{C}_{3} \mathrm{~N}_{4}$ and $50: 2$ $\mathrm{CN}-\mathrm{PDPB}$ photocatalysts.

Transient photocurrent analysis is also a widely used typical method to investigate the electron-hole separation effect for a material. ${ }^{46}$ In Fig. 13, it can be seen that the photocurrent of $50: 2 \mathrm{CN}-\mathrm{PDPB}$ is much larger than the photocurrent of pure $\mathrm{g}$ $\mathrm{C}_{3} \mathrm{~N}_{4}$, indicating higher separation and transfer efficiency of photo-generated electrons and holes due to the synergetic effect of $\mathrm{g}-\mathrm{C}_{3} \mathrm{~N}_{4}$ and PDPB.

The effects of benzoquinone (BQ, a typical ${ }^{\circ} \mathrm{O}_{2}{ }^{-}$scavenger) and disodium oxalate $\left(\mathrm{Na}_{2} \mathrm{C}_{2} \mathrm{O}_{4}\right.$, a typical hole scavenger $)$ on the photodegradation of RhB in the presence of $50: 2 \mathrm{CN}-\mathrm{PDPB}$ are investigated. From the Fig. 14, we can see that the BQ clearly inhibits the photodegradation of $\mathrm{RhB}$, but the $\mathrm{Na}_{2} \mathrm{C}_{2} \mathrm{O}_{4}$ lightly decreases the photodegradation of $\mathrm{RhB}$, indicating that the ${ }^{\circ} \mathrm{O}_{2}{ }^{-}$and the holes are all effective for the degradation of $\mathrm{RhB}$ but the ${ }^{\circ} \mathrm{O}_{2}{ }^{-}$is the main active species for the RhB degradation.

On the basis of the above experiments and results, the mechanism is explained in Fig. 15. With irradiation of light, both $\mathrm{g}-\mathrm{C}_{3} \mathrm{~N}_{4}$ and $\mathrm{PDPB}$ can be excited to produce photogenerated electrons and holes. The conduction band (CB) position of PDPB $(-1.78 \mathrm{eV})$ is more negative than that of $\mathrm{g}$ $\mathrm{C}_{3} \mathrm{~N}_{4}(-1.13 \mathrm{eV})$, and the valence band $(\mathrm{VB})$ position of $\mathrm{g}-\mathrm{C}_{3} \mathrm{~N}_{4}$ $(+1.57 \mathrm{eV})$ is more positive than that of PDPB $(+0.18 \mathrm{eV}) .^{31}$ Hence, the photo-generated electrons of PDPB can easily transfer to the conduction band $(\mathrm{CB})$ of $\mathrm{g}-\mathrm{C}_{3} \mathrm{~N}_{4}$, while the holes of $\mathrm{g}-\mathrm{C}_{3} \mathrm{~N}_{4}$ can transfer to the valence band (VB) of PDPB. Thus,

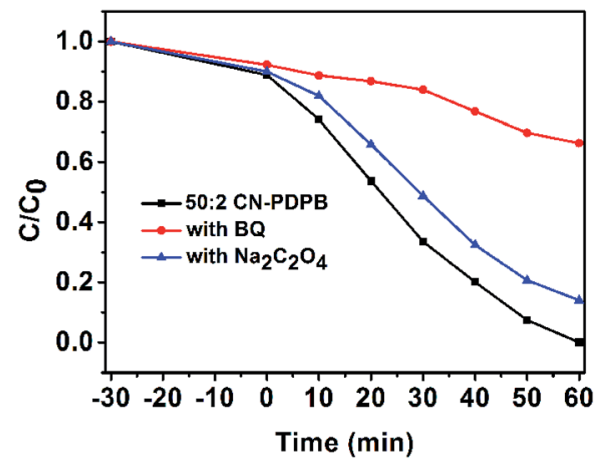

Fig. 14 Effects of $\mathrm{BQ}$ and $\mathrm{Na}_{2} \mathrm{C}_{2} \mathrm{O}_{4}$ on $\mathrm{RhB}$ photodegradation catalyzed by $50: 2 \mathrm{CN}$-PDPB photocatalysts.

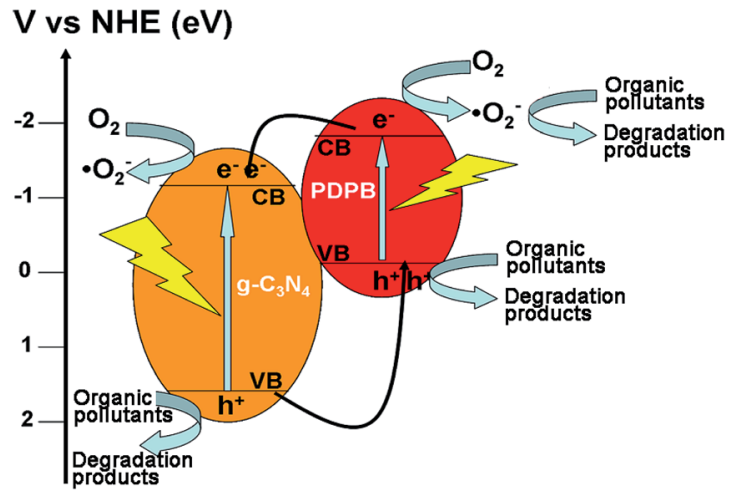

Fig. 15 The proposed photocatalytic mechanism of CN-PDPB composites.

the recombination of photo-generated electrons and holes can be inhibited and an effective charge separation is achieved, resulting in a remarkable enhancement of the photocatalytic activity. Moreover, the major possible reactions can be displayed as follows:

$$
\begin{aligned}
& \mathrm{CN}-\mathrm{PDPB}+h v \rightarrow \mathrm{g}-\mathrm{C}_{3} \mathrm{~N}_{4}{ }^{*}-\mathrm{PDPB} * \\
& \text { g- } \mathrm{C}_{3} \mathrm{~N}_{4}{ }^{*}-\mathrm{PDPB}^{*} \rightarrow \mathrm{g}-\mathrm{C}_{3} \mathrm{~N}_{4}\left(\mathrm{e}^{-} \mathrm{e}^{-} / \mathrm{h}^{+} \mathrm{h}^{+}\right)-\operatorname{PDPB}\left(\mathrm{e}^{-} \mathrm{e}^{-} / \mathrm{h}^{+} \mathrm{h}^{+}\right) \\
& \text {g- } \mathrm{C}_{3} \mathrm{~N}_{4}\left(\mathrm{e}^{-} \mathrm{e}^{-} / \mathrm{h}^{+} \mathrm{h}^{+}\right)-\text {PDPB }\left(\mathrm{e}^{-} \mathrm{e}^{-} / \mathrm{h}^{+} \mathrm{h}^{+}\right) \rightarrow \\
& \text { g- } \mathrm{C}_{3} \mathrm{~N}_{4}\left(\mathrm{e}^{-} \mathrm{e}^{-} \mathrm{e}^{-} / \mathrm{h}^{+}\right)-\operatorname{PDPB}\left(\mathrm{e}^{-} / \mathrm{h}^{+} \mathrm{h}^{+} \mathrm{h}^{+}\right) \\
& \mathrm{e}^{-}+\mathrm{O}_{2} \rightarrow \mathrm{O}^{-} \\
& \mathrm{O}_{2}{ }^{-}+\text {organic pollutants } \rightarrow \text { degradation products } \\
& \mathrm{h}^{+}+\text {organic pollutants } \rightarrow \text { degradation products }
\end{aligned}
$$

The stability of photocatalyst is another important issue for a photocatalyst. The recycling runs in the photodegradation of RhB in the presence of $50: 2$ CN-PDPB are carried out. Fig. 16 shows that the photocatalytic degradation degree of RhB still remains high after 5 cycles, manifesting the catalyst has good photocatalytic stability.

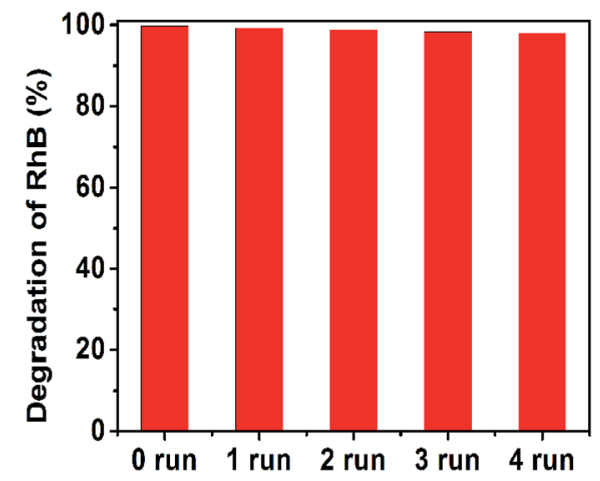

Fig. 16 Effect of cycling runs on $\mathrm{RhB}$ degradation in the presence of 50 : 2 CN-PDPB under visible-light irradiation. 


\section{Conclusions}

In summary, a new photocatalyst has been prepared by compounding $\mathrm{g}-\mathrm{C}_{3} \mathrm{~N}_{4}$ and the polymer PDPB via a facile method. The photocatalytic activity of CN-PDPB composites is much higher than that of the pure catalysts $\left(\mathrm{g}-\mathrm{C}_{3} \mathrm{~N}_{4}\right.$ or PDPB), which is confirmed by the photocatalytic degradation of $\mathrm{RhB}$ and phenol under simulated solar light or visible light. With the increase of PDPB content, the photocatalytic activity increases at first and then decreases, and 50:2 CN-PDPB has the highest photocatalytic activity. The enhanced photocatalytic activity may be caused by the increased charge separation which can be attributed to the synergistic effect between $\mathrm{g}-\mathrm{C}_{3} \mathrm{~N}_{4}$ and PDPB. In addition, the photocatalytic stability of the catalyst is good. This study is hopeful to provide some experience for the synthesis of other polymer composited $\mathrm{g}-\mathrm{C}_{3} \mathrm{~N}_{4}$ or other semiconductor composited PDPB in the application of photocatalysis and other fields.

\section{Acknowledgements}

The authors wish to express their deepest and sincerest recognition of Prof. András Dombi a key figure in the topic of photocatalytic materials for the degradation of contaminants of environmental concern. This work was financially supported by National Nature Science Foundation of China (21407049, 21377038, 21237003 and 21677048), China Postdoctoral Science Foundation (2015T80409), Shanghai Pujiang Program (14PJ1402100), the Science and Technology Commission of Shanghai (16JC1401400) and the Science and Technology Commission of Jiangsu Province (BC2015135).

\section{References}

1 A. Fujishima and K. Honda, Nature, 1972, 238, 37-38.

2 C. Chen, W. Ma and J. Zhao, Chem. Soc. Rev., 2010, 39, 42064219.

3 S. Dong, J. Feng, M. Fan, Y. Pi, L. Hu, X. Han, M. Liu, J. Sun and J. Sun, RSC Adv., 2015, 5, 14610-14630.

4 W. Wang, Y. Liu, J. Qu, Y. Chen and Z. Shao, RSC Adv., 2016, 6, 40923-40931.

5 H. Li, L. Zhou, L. Z. Wang, Y. D. Liu, J. Lei and J. L. Zhang, Phys. Chem. Chem. Phys., 2015, 17, 17406-17412.

6 H. Li, X. Shen, Y. Liu, L. Wang, J. Lei and J. Zhang, J. Alloys Compd., 2016, 687, 927-936.

7 M. Nasir, J. Lei, W. Iqbal and J. Zhang, Appl. Surf. Sci., 2016, 364, 446-454.

8 S. G. Kumar and K. S. R. K. Rao, RSC Adv., 2015, 5, 3306-3351. 9 Y. Xu, H. Xu, H. Li, J. Xia, C. Liu and L. Liu, J. Alloys Compd., 2011, 509, 3286-3292.

10 Y. Liu, P. Zhang, B. Z. Tian and J. L. Zhang, ACS Appl. Mater. Interfaces, 2015, 7, 13849-13858.

11 S. Singh and N. Khare, RSC Adv., 2015, 5, 96562-96572.

12 J. Lei, Y. Chen, F. Shen, L. Wang, Y. Liu and J. Zhang, J. Alloys Compd., 2015, 631, 328-334.

13 H. Li, L. Wang, Y. Liu, J. Lei and J. Zhang, Res. Chem. Intermed., 2016, 42, 3979-3998.
14 X. C. Wang, K. Maeda, A. Thomas, K. Takanabe, G. Xin, J. M. Carlsson, K. Domen and M. Antonietti, Nat. Mater., 2009, 8, 76-82.

15 Z. W. Zhao, Y. J. Sun and F. Dong, Nanoscale, 2015, 7, 15-37.

16 J. Hong, X. Xia, Y. Wang and R. Xu, J. Mater. Chem., 2012, 22, 15006-15012.

17 Y. Xu, M. Xie, S. Huang, H. Xu, H. Ji, J. Xia, Y. Li and H. Li, RSC Adv., 2015, 5, 26281-26290.

18 X. F. Chen, J. S. Zhang, X. Z. Fu, M. Antonietti and X. Wang, J. Am. Chem. Soc., 2009, 131, 11658-11659.

19 L. Zhang, X. Chen, J. Guan, Y. Jiang, T. Hou and X. Mu, Mater. Res. Bull., 2013, 48, 3485-3491.

20 Y. Zhang, T. Mori, J. Ye and M. Antonietti, J. Am. Chem. Soc., 2010, 132, 6294-6295.

21 S. C. Yan, Z. S. Li and Z. G. Zou, Langmuir, 2010, 26, 38943901.

22 J. Lei, Y. Chen, L. Wang, Y. Liu and J. Zhang, J. Mater. Sci., 2015, 50(9), 3467-3476.

23 L. Zhou, L. Wang, J. Lei, Y. Liu and J. Zhang, Catal. Commun., 2017, 89, 125-128.

24 L. Zhou, L. Wang, J. Zhang, J. Lei and Y. Liu, Eur. J. Inorg. Chem., 2016, 5387-5392.

25 Y. S. Xu and W. D. Zhang, ChemCatChem, 2013, 5, 23432351.

26 S. Z. Wu and K. Li, Appl. Surf. Sci., 2015, 324, 324-331.

27 H. J. Yan and Y. Huang, Chem. Commun., 2011, 47, 41684170.

28 D. S. Wang, H. T. Sun, Q. Z. Luo, X. L. Yang and R. Yin, Appl. Catal., B, 2014, 156, 323-330.

29 S. Gawande and S. R. Thakare, ChemCatChem, 2012, 4, 17591763.

30 L. Ge, C. C. Han and J. Liu, J. Mater. Chem., 2012, 22, 1184311850.

31 S. Ghosh, L. Ramos, S. Remita, A. Dazzi and H. Remita, Nat. Mater., 2015, 14, 505-511.

32 S. Sardar, P. Kar, H. Remita, B. Liu, P. Lemmens, S. K. Pal and S. Ghosh, Sci. Rep., 2015, 5, 17313-17326.

33 Y. Xu, M. Xie, S. Huang, H. Xu, H. Ji, J. Xia, Y. Li and H. Li, RSC Adv., 2015, 5, 26281-26290.

34 Y. Xu, S. Huang, M. Xie, Y. Li, H. Xu, L. Huang, Q. Zhang and H. Li, RSC Adv., 2015, 5, 95727-95735.

35 X. Jian, X. Liu, H. M. Yang, J. G. Li, X. L. Song, H. Y. Dai and Z. H. Liang, Appl. Surf. Sci., 2016, 370, 514-521.

36 S. W. Cao, Y. P. Yuan, J. Fang, M. M. Shahjamali, F. Y. C. Boey, J. Barber, S. C. J. Loo and C. Xue, Int. J. Hydrogen Energy, 2013, 8, 1258-1266.

37 L. Ge, C. Han, J. Liu and Y. Li, Appl. Catal., A, 2011, 409-410, 215-222.

38 Y. Wang, X. Wang and M. Antonietti, Angew. Chem., Int. Ed., 2012, 51, 68-89.

39 A. Vinu, Adv. Funct. Mater., 2008, 18, 816-827.

40 B. Subash, B. Krishnakumar, M. Swaminathan and M. Shanthi, Res. Chem. Intermed., 2013, 39, 3181-3197.

41 K. Yadav, M. Giri and N. Jaggi, Res. Chem. Intermed., 2015, 41, 9967-9978.

42 A. K. L. Sajjad, S. Shamaila, B. Z. Tian, F. Chen and J. L. Zhang, Appl. Catal., B, 2009, 91, 397-405. 
43 C. Zeng, M. Guo, B. Tian and J. Zhang, Chem. Phys. Lett., 2013, 575, 81-85.

44 C. Zeng, B. Tian and J. Zhang, J. Colloid Interface Sci., 2013, 46 K. Dai, L. Lu, Q. Liu, G. Zhu, X. Wei, J. Bai, L. Xuan and 405, 17-21.
45 X. Liu, L. J. Chen, R. Y. Chen, Z. Chen, X. Chen and X. Zheng, Res. Chem. Intermed., 2015, 41(6), 3623-3636.

H. Wang, Dalton Trans., 2014, 43, 6295-6299. 